\title{
Towards Rational Design Method for Strengthening of Concrete Structures by External Bonding
}

\author{
Ueda, T. ${ }^{1}$ Zhang, D. ${ }^{1}$ and Furuuchi, H. ${ }^{1}$
}

\begin{abstract}
Many infrastructures need to be repaired or strengthened due to various reasons, such as unexpected deterioration and changes in performance requirement. This paper presents the following recent achievements by the authors' group on design method for flexural strengthening of concrete structures by external bonding; (i) fracture characteristics of interface between substrate concrete and cementitious overlay, (ii) crack spacing of flexural strengthened beams, which affects debonding strength, (iii) strengths of intermediate crack (IC) debonding and end peeling, (iv) strength of concrete cover separation, and (v) effectiveness of strengthening by external bonding. A unified approach for flexural strengthening by steel plate, fiber reinforced polymer laminate and cementitious overlay, for both intermediate crack (IC) debonding, including end peeling, and concrete cover separation is presented with consideration of crack spacing in the strengthened members. Appropriate interfacial roughness to achieve efficient interface bond property is clarified and the concept of effectiveness of strengthening is proposed for better strengthening design.
\end{abstract}

Keywords: Strengthening, concrete structure, external bonding, overlay, steel plate, FRP laminate, IC debonding, concrete cover separation.

\section{Introduction}

We have been constructing abundant infrastructures to make the people's life of higher quality. Unfortunately, it is the fact that many infrastructures need to be repaired or strengthened due to the various reasons, such as unexpected deterioration and changes in performance requirement. Repairing and strengthening can extend the service life of infrastructures, so that not only the cost but also the resources and energy can be saved, meaning that it would contribute to the global sustainability.

One of the typical repair/strengthening methods for concrete structure is strengthening by external bonding. There are three types of externally bonded materials, which are tension reinforcement for concrete, as follows:

- Steel plate

- FRP laminate

- Cementitious overlay

Both steel and FRP are good tension materials. Before 1990s steel plate was most commonly used, while FRP laminate started to be applied more since the mid-1990s. Overlay with cementitious material needs tension material in it to make itself tension material. Overlay has been accepted well in practical cases. However, it is only considered as a repairing tool to enhance durability in most of the cases. Because of the above historical background, there are practical design guidelines available for external bonded steel plate and FRP laminate, but not for overlay. The most of design guidelines deal with steel plate cases and FRP laminate cases separately.

${ }^{1}$ Lab of Engineering for Maintenance System, Faculty of Engineering, Hokkaido University, Sapporo, JAPAN

Email: ueda@eng.hokudai.ac.jp
The primary technical issue common among externally bonded steel plate, FRP laminate and cementitious overlay is debonding at interface between substrate concrete and bonded tension material. There are three types of debonding failure modes as follows (see Figure 1):

- Intermediate crack (IC) debonding

- Concrete cover separation

- End peeling

There are many studies on the above debonding mechanisms, especially in the case of externally bonded FRP laminate. However, no commonly accepted prediction method which can cover all of steel plate, FRP laminate and cementitious overlay has been established yet.

This paper presents the summary of the outcomes from series of studies done by the authors' group on general design approach for strengthening concrete structures by external bonding, with emphasis on flexural strengthening and cementitious overlay. The following chapters include:

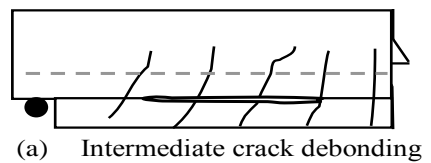

Intermediate crack debonding

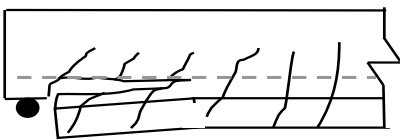

(b) Concrete cover separation

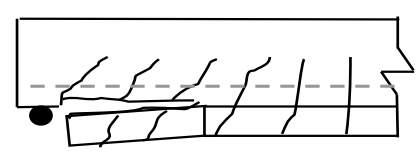

(c) End peeling

Figure 1. Three Types of Debonding Failure Modes 
- Fracture characteristics of interface between substrate concrete and cementitious overlay

- Crack spacing of flexural strengthened beams, which affects debonding strength

- Strengths of IC debonding and end peeling

- Strength of concrete cover separation

- Effectiveness of strengthening by external bonding

\section{Fracture Characteristics of Interface Bet- ween Substrate Concrete and Cementi- tious Overlay [1]}

Debonding at the interface between substrate concrete and strengthening tension material in strengthened members are structural behavior. The debonding obviously depends on the interface fracture material properties, such as bond strength and fracture energy (in tension, shear and flexure). There are various parameters on the fracture properties, such as substrate concrete strength and roughness, adhesive strength and stiffness, and strength and stiffness of externally bonded material.

An experimental study was conducted on the fracture characteristics of polymer cementitious material (PCM)-substrate concrete interface. The parameters were interface roughness, $R_{a}$ (see Figure 2), strength (4 levels; LS, MLS, MHS and HS) and coarse aggregate type (river gravel and crushed stone, CS) of substrate concrete. Splitting tensile, direct shear and three point bending tests were conducted to obtain bond tensile, shear and flexural strength respectively as shown in Figure 3. Fracture energy was also obtained through the three point bending test. The followings are the findings:

(1) As shown in Figure 4, experimental results indicate that interface bond strength and fracture energy without surface treatment are fairly low compared to those with surface treatment. The bond strength and fracture energy increase with interface roughness, $R_{a}$. The maximum bond tensile and shear strength can be achieved with a small roughness $R_{a} \approx 0.4 \mathrm{~mm}$. The maximum bond flexural strength and mode I fracture energy can be reached with $R_{a} \approx 1 \mathrm{~mm}$.

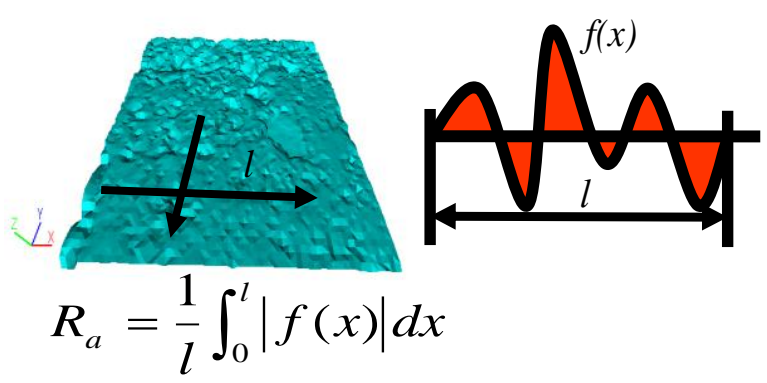

Figure 2. Evaluation of Interface Roughness $R_{a}$

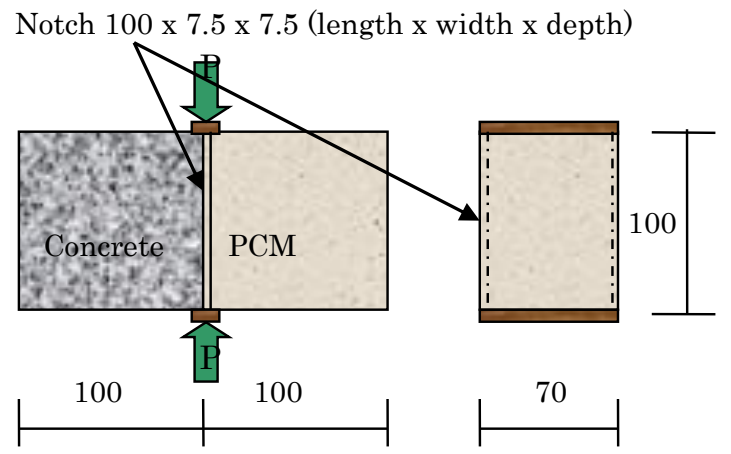

(a) Splitting tensile test (unit: $\mathrm{mm}$ )

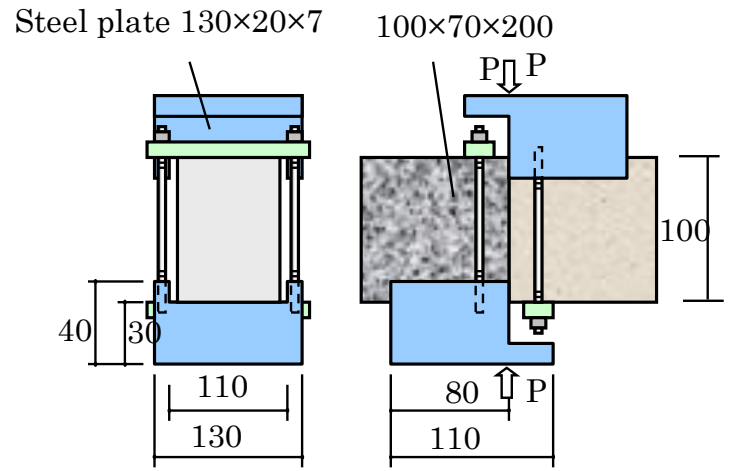

(b) Direct shear test (unit: $\mathrm{mm}$ )

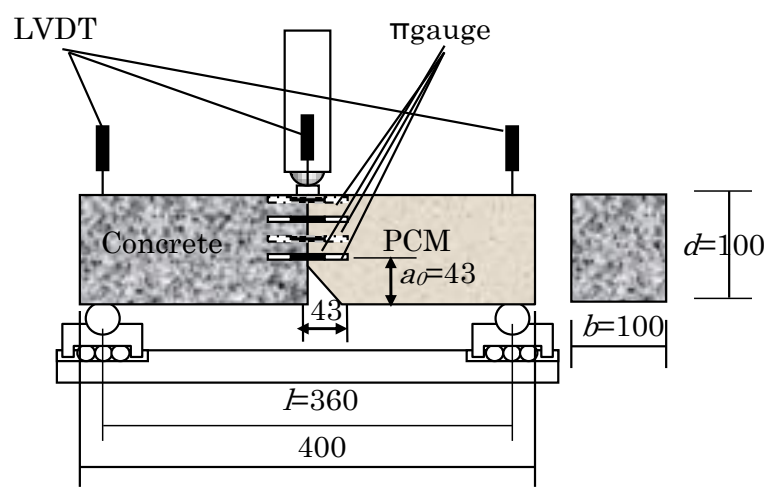

(c) Three point bending test setup (unit: $\mathrm{mm}$ )

Figure 3. Tests for Bond Strength and Fracture Energy

(2) Regarding the single mode (Mode I or Mode II) bond and fracture properties as well as retrofitting costs, the $R_{a} \approx 1 \mathrm{~mm}\left(0.9 \leq R_{a} \leq 1.1\right.$ $\mathrm{mm}$ ) could be the optimum value of interface roughness for substrate concrete with normal size aggregate $\left(10 \leq D_{\max } \leq 25 \mathrm{~mm}\right)$. The corresponding optimum treatment depth with water jet treatment is $2-2.5 \mathrm{~mm}$ from the substrate surface.

(3) For any substrate concrete tested in this paper, the bond flexural failure happens at PCMconcrete interface adhesion layer when interface roughness is rather small and at concrete cohesion layer when the roughness is rather large. Both 


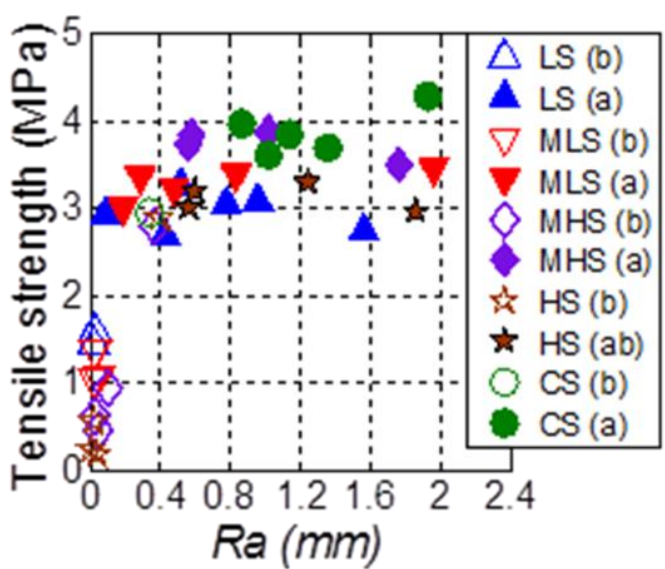

(a) Tensile strength

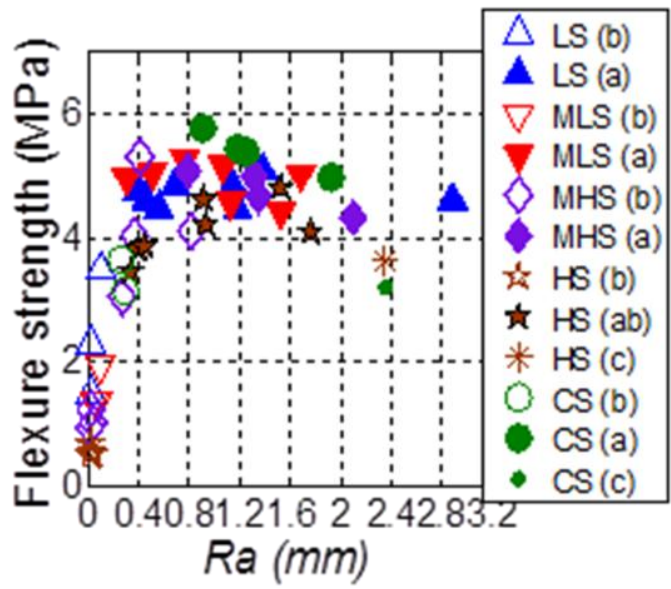

(c) Flexural strength

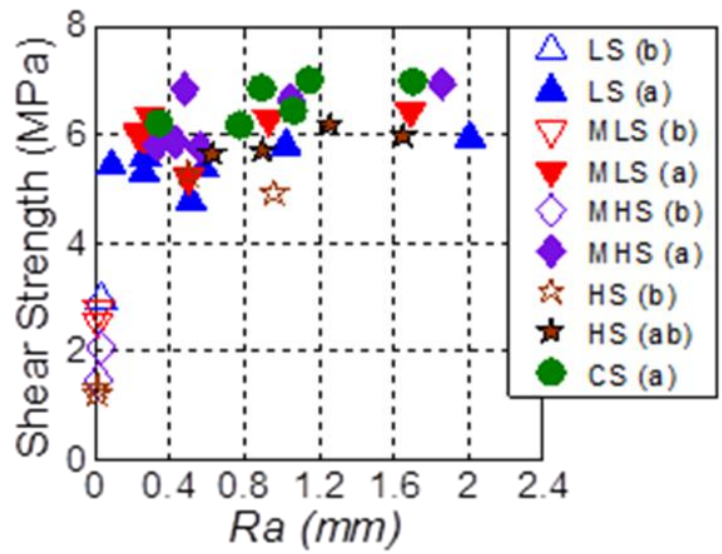

(b) Shear strength

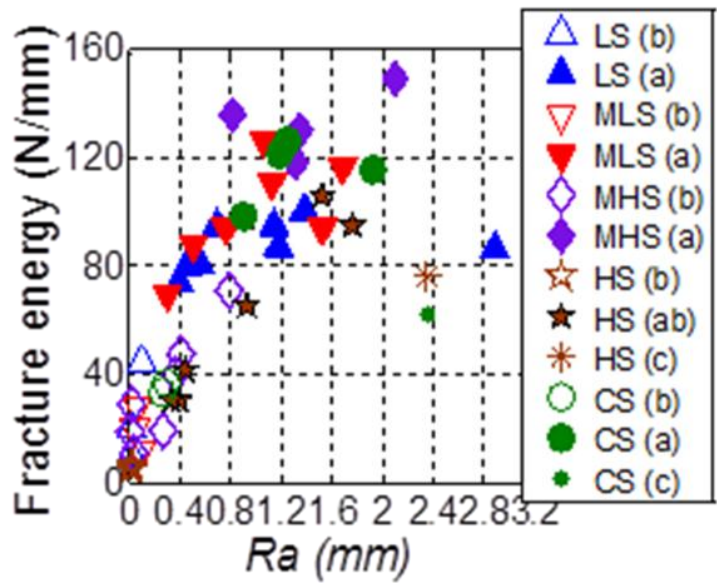

(d) Fracture energy

Figure 4. Effects of Interface Roughness on Bond Strength and Fracture Energy

the bond strength and fracture energy in the latter case are larger than those of the former case.

(4) The effect of aggregate type (crushed stone or river stone) on the interface bond strength and fracture energy is not distinct.

(5) The interface tension softening model taking into account effects of interfacial fracture energy, tensile strength and maximum crack width is presented based on the experimental results with modified J-integral method as follows:

$$
\frac{\sigma}{f_{s t}}=\left(1-\sqrt{\frac{w}{w_{\max }}}\right)^{b}
$$

where $b$ is a non-dimensional material constant defined as a function of the bond tensile strength $f_{s t}$, the bond fracture energy $G_{f}$ and the maximum crack width $w_{\max }$ :

$b=\frac{\alpha f_{s t} w_{\max }}{G_{f}}$ where $a$ is determined to be 322 by fitting the equation to the calculated $\sigma-w$ data. The maximum crack width $w_{\max }$ is taken as $0.20 \mathrm{~mm}$ for failure in the concrete cohesion layer (failure type a) or in the mixed layer between the concrete cohesion layer and the PCM adhesion layer (failure type $\mathrm{ab}$ ) and as $0.10 \mathrm{~mm}$ for failure in the adhesion layer (failure type b) or in the PCM cohesion layer (failure type c). The calculated results by Equations 1 and 2 are compared with the tested results as shown in Figure 5.

\section{Crack Spacing of Flexural Strengthened Beams [2]}

Cracks play a major role to determine member failure mode and ultimate capacity. Debonding in strengthened members is no exception. Intermediate crack debonding and end peeling always start at flexural or shear crack in a strengthened member. 


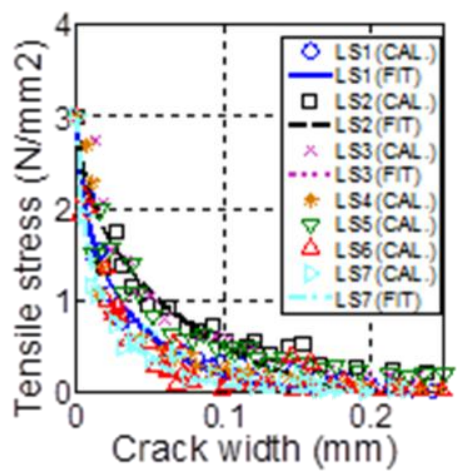

(a) LS series

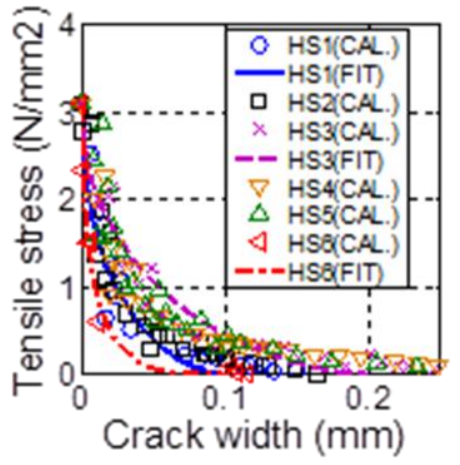

(d) HS sries

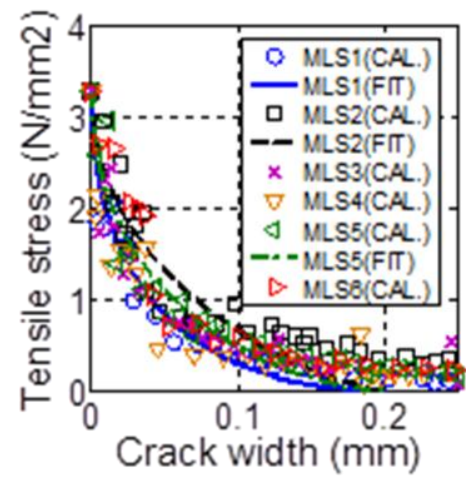

(b) MLS æries

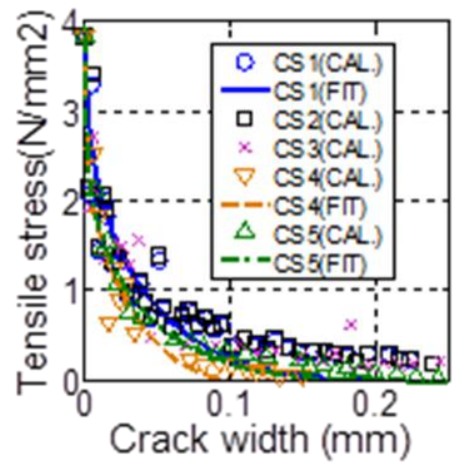

(e) CS series

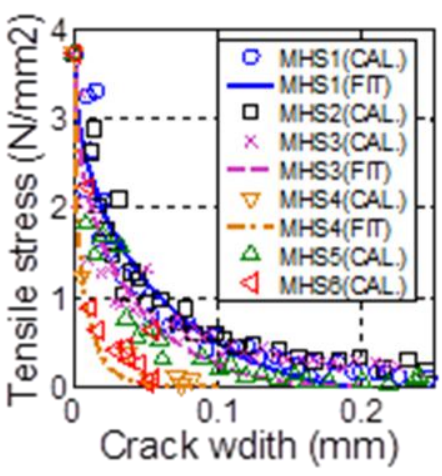

(c) MHS series

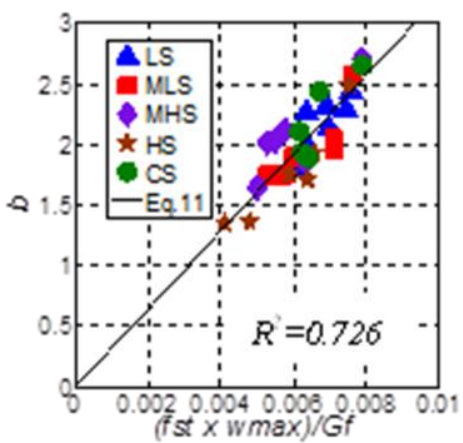

(f) Parameter $b$

Figure 5. Tested and Proposed Tension Softening

When the transferred bond stress within a distance to the next crack and the end of bonded strengthening material is greater than the bond strength, IC debonding and end peeling would occur, leading to member failure (see section: Strengths of IC Debonding and End Peeling). Concrete cover separation also initiates at flexural or shear crack. The distance from the end of bonded strengthening material to the first crack is a controlling parameter for concrete cover separation strength (see section: Strength of Concrete Cover Separation).

A series of studies on average flexural crack spacing in concrete member strengthened by external bonding were conducted and the findings are as follows:

(1) We show that current models of different structural codes for estimating average crack spacing of beams with multilayered reinforcement are inaccurate when applied to overlay strengthened $\mathrm{RC}$ beams with reinforcement layers, both in substrate concrete and overlay, although these two kinds of beams are similar in that reinforcement is multilayered. One of the main reasons for this mismatch is the different initiation location of tensile cracks between the substrate concrete and overlay. However, substituting in the current structural codes only for the valid predicttion of average crack spacing will not suffice, because the cracking mechanism is not clear. Moreover, existing empirical equations do not apply to overlay-strengthened beam with reinforcement in overlay.

(2) We developed a crack spacing model by considering the equilibrium and compatibility equations of overlay-strengthened beam element. In case of cementitious overlay, flexural crack may initiate either in substrate concrete or overlay because the strength of overlay is usually higher than that of substrate concrete. Using the force equilibrium in effective substrate concrete and overlay, stabilized crack spacing can be calculated in the substrate concrete and overlay as follows (see Figure 6):

$$
\begin{gathered}
S_{c s}=\frac{3 f_{c t}\left(A_{c t}+A_{o t} \frac{E_{o}}{E_{c}}\right)}{\left(\sum O_{r} \tau_{b c m}+\sum O_{s} \tau_{b o m}\right)} \\
S_{o s}=\frac{3 f_{o t}\left(A_{c t} \frac{E_{c}}{E_{o}}+A_{o t}\right)}{\left(\sum O_{r} \tau_{b c m}+\sum O_{s} \tau_{b o m}\right)}
\end{gathered}
$$

where $O_{r}$ and $O_{s}$ denote the perimeter of reinforcement in concrete and overlay respectively, $A_{c t}$ and $A_{o t}$ denote the effective tension area of concrete and overlay. The peak bond stress $\tau b c m$ or $\tau_{\text {bom }}$ as shown in Figure 6(b) is calculated using the fib Model Code 2010 equation as follows: 


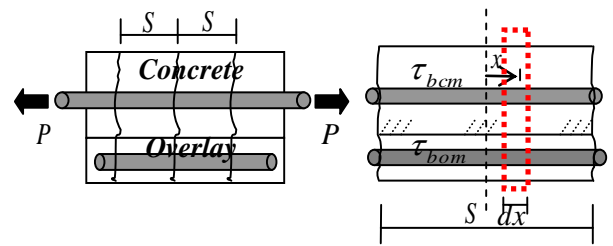

(a) Uniaxial tension on composite (b) Bond stress distribution

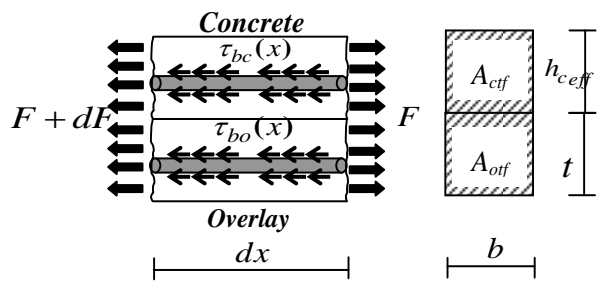

(c) Free body diagram

Figure 6. Element Analysis of Composite

$\tau_{b c(o) m}=5.5 \cdot\left(\frac{f_{c(o)}^{\prime}}{20}\right)^{0.25}$ for splitting failure with

transverse reinforcement

$\tau_{b c(o) m}=5.0 \cdot\left(\frac{f^{\prime}{ }_{c(o)}}{20}\right)^{0.25}$ for splitting failure without

transverse reinforcement

$\tau_{b c(o) m}=1.25 \sqrt{f_{c(o)}^{\prime}}$ for pull-out failure

where $f_{c(0)}^{\prime}$ denotes the cylinder compressive strength of concrete (overlay) in MPa. Once the crack initiates in either layer of concrete or overlay, it will propagate to another layer due to the reduced stiffness of cracked section, therefore the stabilized crack spacing of overlay strengthened composite $S_{s}$ depends on the lesser of $S_{c s}$ and $S_{o s}$, which means

$S_{s}=\min \left(S_{c s}, S_{o s}\right)$

Considering the effect of strain gradient, the average crack spacing of overlay strengthened beam under flexure load can be predicted as follows:

$$
S_{s f}=k_{1} \min \left(S_{c s}, S_{o s}\right)
$$

where $k_{1}$ is the coefficient to account for strain gradient $=\left(\varepsilon_{1}+\varepsilon_{2}\right) / 2 \varepsilon_{1}$ according to CSA S474 (2004), $\varepsilon_{1}$ and $\varepsilon_{2}$ are the largest; and smallest tensile strains in the effective tension zone, $k_{1}$ has the maximum value of 1 in case of uniaxial load and minimum value of 0.5 .

(4) For the case of FRP laminate or steel plate strengthening, the stabilized flexural crack spacing of strengthened $\mathrm{RC}$ beam is given by

$$
S_{s f}=\frac{3 k_{1} f_{c t} A_{c t}}{\left(\sum O_{r} \tau_{s c}+b_{f} \tau_{(S t) F R P}\right)}
$$

where $b_{f}$ denotes the bond width of steel plate or FRP laminate. $\tau_{s c}$ and $\tau_{(S t) F R P}$ denote the peak bond stress at the reinforcement-concrete interface and the steel/FRP-concrete interface at the stabilized crack stage, which can be calculated as following:

$$
\begin{aligned}
& \tau_{s c}=1.25 \sqrt{f^{\prime}{ }_{c}} \\
& \tau_{F R P}=1.25 f_{t} \\
& \tau_{S t}=0.28 \sqrt{f^{\prime}{ }_{c}}
\end{aligned}
$$

(5) To validate the proposed models, we compared the predicted values of the average crack spacing based on the proposed model with a series of experimental investigations available in the literature that involved various types of beam elements (see Figure 7). The proposed models perform satisfactorily in measured response from the experimental work, both for steel bars or FRP grid-reinforced overlay and conventional RC beam with single or multilayered reinforcement. The proposed models also perform satisfactorily for steel plate and FRP laminate strengthening. Therefore, we can apply this model as a practical means of predicting the accurate average stabilized crack spacing in designing overlaystrengthened or conventional RC beams.

\section{Strengths of IC Debonding and End Peeling [3]}

A study on intermediate crack (IC) debonding, including end peeling, in members with flexural strengthening by Polymer Cement Mortar (PCM) overlay was conducted to propose the prediction method for IC debonding in overlay end zone (zone I), shear flexure zone (zone II) and constant moment zone (zone III) as shown in Figure 8. The followings are the outcomes of the study:

(1) A simplified pure shear (pullout) specimen is analyzed first, and a bilinear bond-slip relationship of the PCM-concrete interface constitutive behavior is assumed. The theoretical maximum bond strength depends on the geometric properties of the PCM overlay, material properties of the strengthening bars, and the fracture energy of the PCM-concrete interface that is a function of the substrate concrete properties. A unified equation for calculation of bond strength for any given bond length is then developed with reference to the current available models for steel plate and FRP sheet strengthening as follows:

$P_{u}=\alpha P_{\max }$

$P_{\max }=\sqrt{2 n_{s} b G_{i} E_{s} A_{s}}=b \sqrt{2 G_{i} \frac{n_{s} E_{s} A_{s}}{b}}$

$\alpha=\left\{\begin{array}{cc}\sin \left(\frac{\pi}{2} \frac{L_{b}}{L_{e}}\right) & L_{b} \leq L_{e} \\ 1 & L_{b}>L_{e}\end{array}\right.$ 


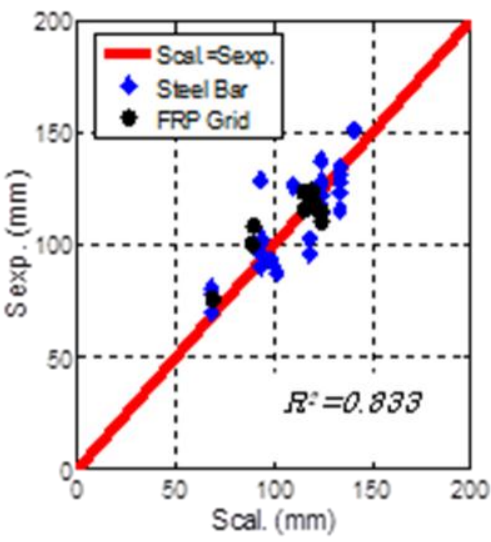

(a) Overlay strengthened $\mathrm{RC}$ be am

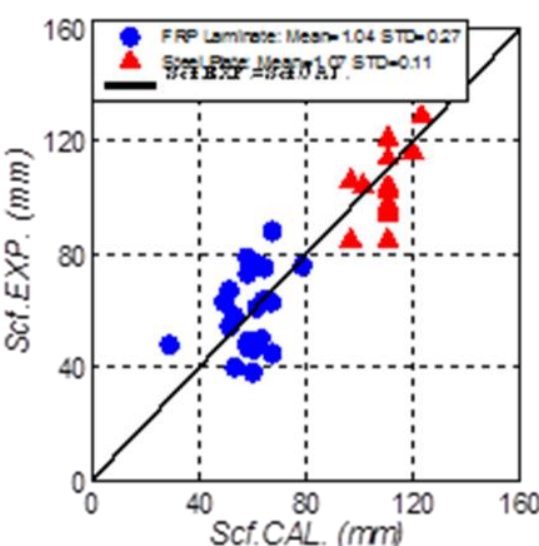

(b) FRP laminatelSteel platestrengthened $\mathrm{RC}$ beam

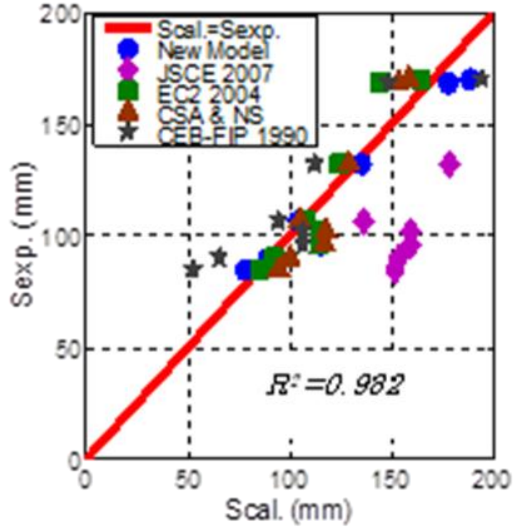

(c) Conventional RC beam

Figure 7. Comparison with New Proposed Model

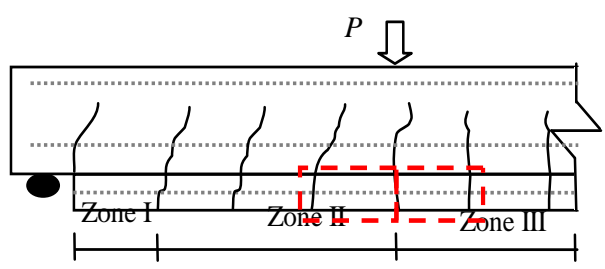

(a) Illustration of zone distribution

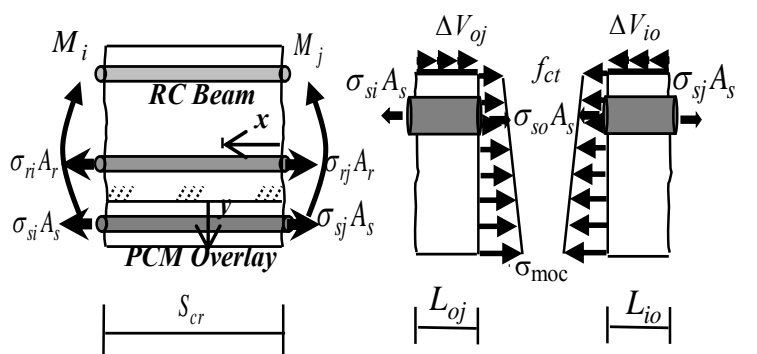

(b) An example (c) Shear transfer in PCM overlay element

(Zero-slip point)

Figure 8. Illustration of Four-Point Bending Beam

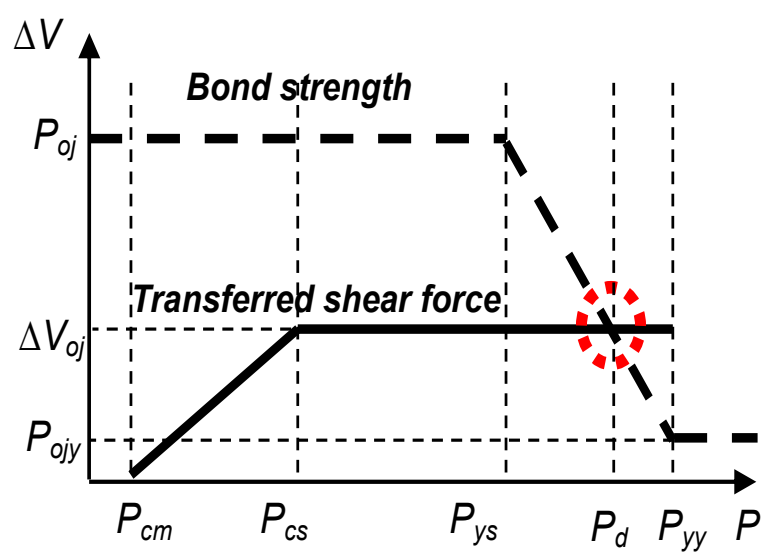

Figure 9. Debonding Criteria

$$
\begin{aligned}
& L_{e}=\frac{\pi}{2} \frac{\sqrt{2 G_{i} n E_{s} A_{s} / b}}{\tau_{i \max }} \\
& \tau_{i \max }=C_{\pi i}\left(\frac{1}{f_{c t}}+\frac{1}{f_{c}^{\prime}}\right)^{-1} \\
& G_{i}=C_{G i} \cdot f_{c}^{\prime 1 / 3}
\end{aligned}
$$

where $G_{i}$ is the fracture energy of overlayconcrete interface, $E_{s}, A_{s}$, and $n_{s}$ denote modulus of elasticity, cross-sectional area and number of strengthening bars respectively, and $b$ is the width of PCM overlay. $f_{c t}$ and $f_{c}$ are the tensile and cylinder compression strength of substrate concrete, respectively. According to experimental results, the mean value of $C_{i i}$ and $C_{G i}$ can be taken as 0.711 and 0.075 respectively.

(2) The tension-stiffening effect of the PCM to the strengthening bar and the moment gradient are two sources of generating shear stress along the PCM-concrete interface (see Figure 8). The shear force transfer mechanism of the PCM-concrete interface in the case of a beam subjected to bending load and the debonding process for an element with short or long bond length in different locations is analyzed with the stress and strain distribution along the interfaces.

(3) The theoretical bond strength indicates an upper limit on the transferred shear force for different applied loads. The debonding occurs when the transferred shear force is equal to or greater than the bond strength. The debonding strength can then be determined on the basis of the intersection point of two curves representing the transferred shear force and the bond strength of the PCM-concrete interface (see Figure 9). By comparing the debonding strength with the oretical flexure and shear strength of a given 


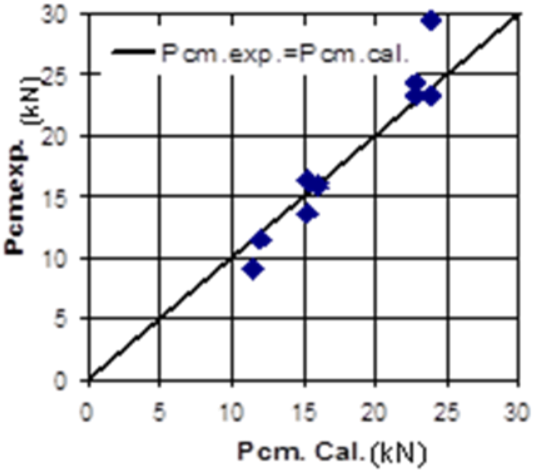

(a) PCM cracking load

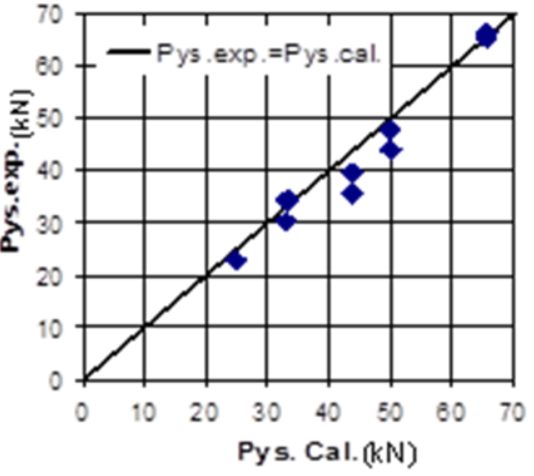

(b) Strengthening bar yielding load at

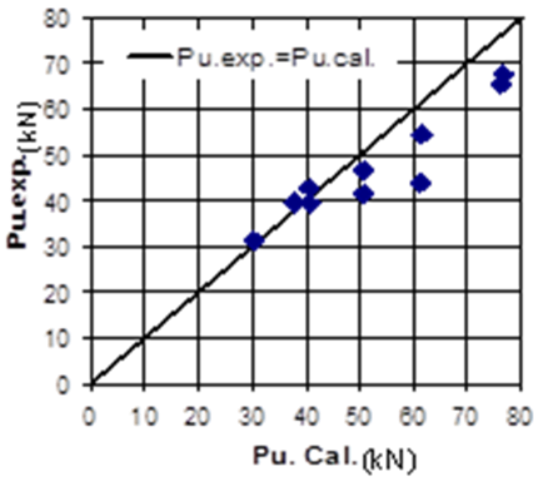

(c) Peak load

cracked section

Figure 10. Comparison between Analytical and Experimental Results

strengthened beam, the peak load and failure mode can be determined according to the minimum strength of the strengthened beam.

(4) The reliability and accuracy of the proposed analytical procedure have been successfully veryfied by comparing the analytical and experimental values of the PCM-strengthened beam in a bending test database (see Figure 10).

\section{Strength of Concrete Cover Separation [4]}

An experimental study was conducted to develop the prediction analytical model for strength of concrete cover separation. The behaviors of PCM or HPFRCC overlay strengthened with steel bars or FRP grid failed by concrete cover separation were experimentally and analytically investigated first. Then the analytical model was extended to the case of concrete cover separation in members strengthened by externally bonded steel plate or FRP laminate. The main findings are as follows:

(1) The failure of the concrete cover separation was initiated by the formation of a crack at the edge of overlay caused by its abrupt termination. The crack was further propagated to the level of the tension reinforcement in the substrate concrete beam part and then progressed horizontally along the level of the steel reinforcement and the peak load is reached after the concrete cover separation until (i) the tension reinforcing bar yields or (ii) the entire shear span debonds. A simple analytical approach is developed based on the considerations in concrete near the reinforcing bar closest to the cut-off point of the overlay. The analysis, based on the tooth model (see Figure 11), consists of three stages; the determination of (i) local stress of substrate concrete at the lower face of the reinforcing bar, (ii) tensile stress of the reinforcement in overlay by assuming the monolithic composite action, and

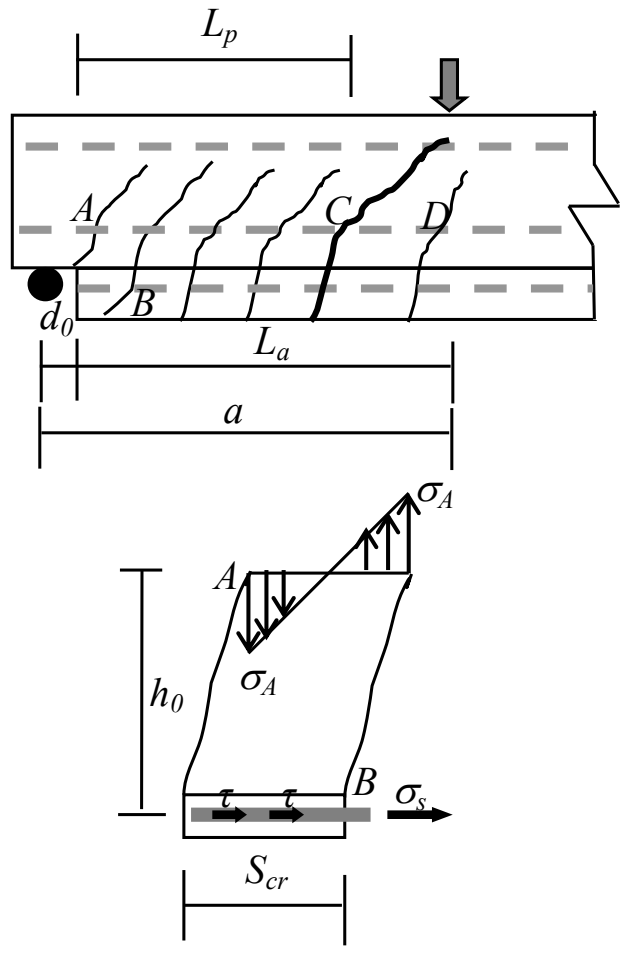

Figure 11. Concrete Tooth Model

(iii) length of concrete cover separation corresponding to the peak load. Using this analytical approach, the peak load of overlay-strengthened beams with concrete cover separation can be predicted by the following equations.

$$
\begin{aligned}
& P_{d y}=\frac{2 M_{r u}}{\left(d_{0}+L_{p}\right)} \\
& L_{p}=\frac{6 h_{0} A_{s}\left(d_{s}-x_{g}\right) M_{r u}}{f_{c t} b S_{c r} I_{s}}
\end{aligned}
$$

where $M_{r u}$ is the bending moment at the tension reinforcement yielding of an unstrengthened (control) beam, and $L_{p}$ is the concrete cover's 
debonding length at the failure load. $d_{0}$ is the distance between the support and the end of the overlay; $h_{0}$ is the net concrete cover height measured from the bottom side of the substrate concrete's reinforcing bar to the center of the external reinforcement; $b$ is the width of the beam; and $A_{s}$ is the cross-sectional area of the external reinforcement (either an FRP grid or a steel bar) inside the overlay; $x_{g}, d_{s}$ and $I_{s}$ are the neutral axis depth of the cracked section with strengthening, the effective depth of the external reinforcement and the transformed moment of inertia of the beam's cracked cross-section in terms of the external reinforcement, respectively; and $f_{c t}$ is the substrate concrete's tensile strength.

(2) By comparing the predicted strength with the theoretical flexure and shear strength of a given

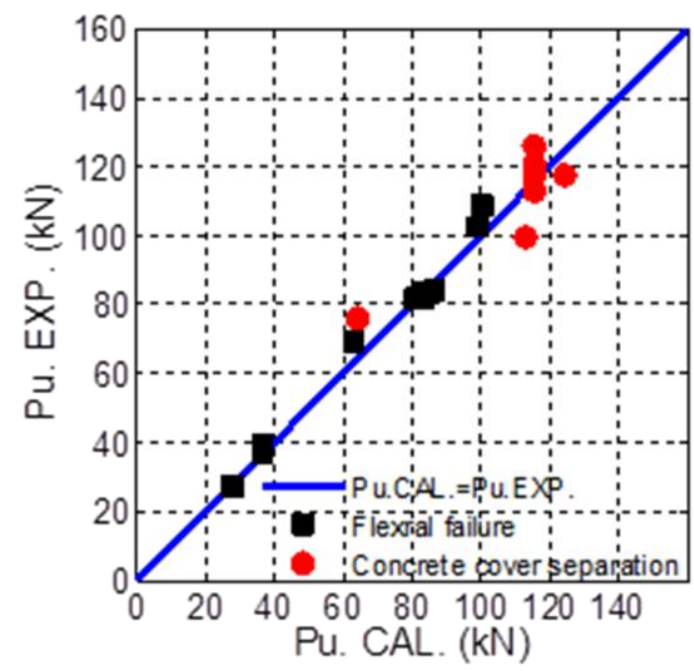

(a) Overlay streng thening strengthened beam, the peak load and failure mode can be determined as the minimum strength of the strengthened beam among those strengths.

(3) The reliability and accuracy of the proposed analytical procedure have been verified by comparing the analytical and experimental values of the overlay-strengthened beam provided in this study as well as the published literatures (see Figure 12).

\section{Effectiveness of Strengthening by External Bonding}

Based on the analytical model for concrete cover separation strength, a concept was presented to determine the efficient strengthening area and

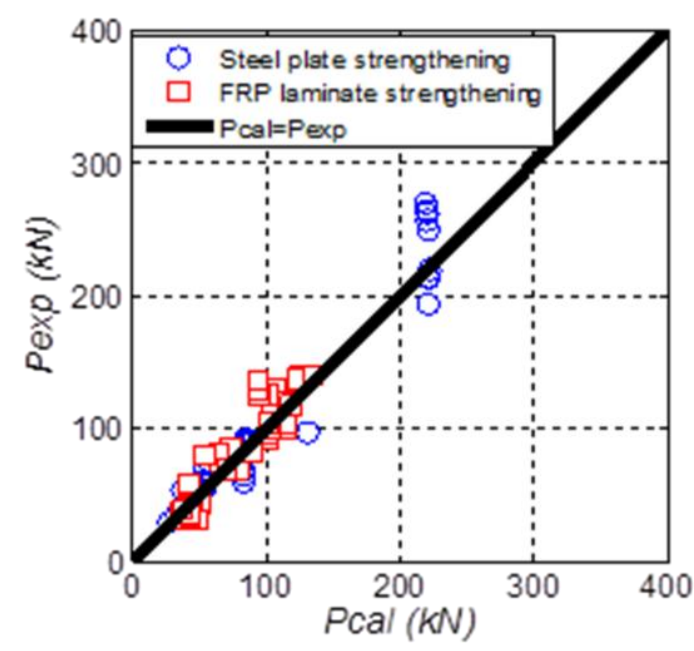

(b) Steel plate and FRP strengthening

Figure 12. Comparison Between Experimental and Analytical Peak Load

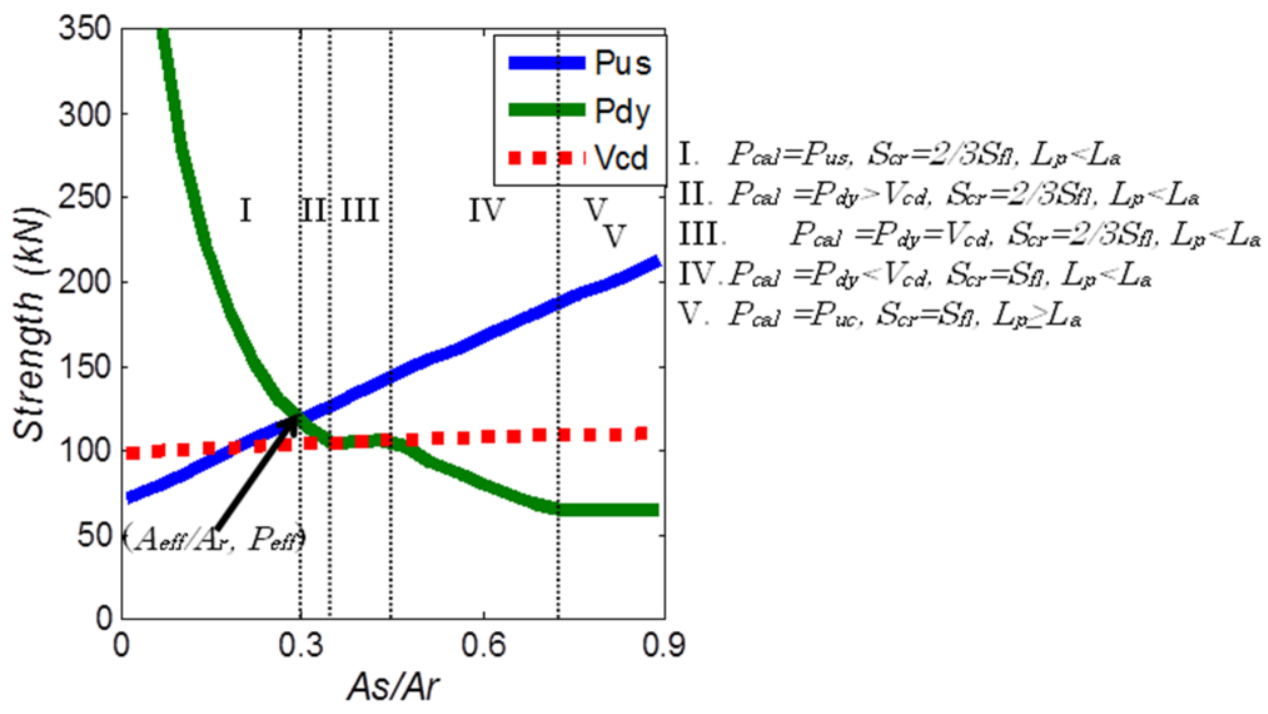

Figure 13. Effective Strengthening Capacity [4] 
effecttive strengthening capacity by predicting the intersection point of the two curves representing the flexure strength $\left(P_{u s}\right)$ and debonding strength $\left(P_{d y}\right)$, both of which vary with the ratio of area of external and internal reinforcement $A_{s} / A_{r}$ (see Figure 13 [4]). Parametric studies clarify the effects of various parameters as follows; (i) when the strengthening reinforcement area is kept constant, bonds that are thicker and narrower have the better efficiency, (ii) the shorter distance between the end of the FRP laminate and the support has the better efficiency, (iii) when external reinforcement's tensile strength is kept constant, smaller external reinforcement's Young's modulus has the better efficiency, and (iv) when external reinforcement's Young's modulus is kept constant, larger external reinforcement's tensile strength has the better efficiency.

For the concrete cover separation the efficiency with FRP laminate and overlay strengthening is generally better than that with steel plate strengthening.

\section{Concluding Remarks}

In order to develop a rational design approach for strengthening of concrete structures by external bonding, it is inevitable to develop prediction methods for various types of debonding strength. For flexural strengthening by steel plate, FRP laminate and cementitious overlay, a unified approach for both intermediate crack (IC) debonding, including end peeling, and concrete cover separation is presented with consideration of crack spacing in strengthened members. Appropriate interfacial roughness to achieve efficient interface bond property is clarified. The concept of effectiveness of strengthening is proposed for better strengthening design.

The followings are the remaining tasks for the rational design approach:

- Develop the unified approach for IC debonding in steel plate, FRP laminate and cementitious overlay strengthened members.

- Develop the debonding criteria with consideration of normal stresses at interface.
- Clarify the effects of chronological effects, such as effects of environmental actions and fatigue, on strengthened member performance.

- Develop the design method for shear strengthening.

\section{Acknowledgement}

This study is a part of the International Collaborative Research, "Life Cycle Prediction and Management of Concrete Structures" adopted by the AsiaAfrica S \& T Strategic Cooperation Promotion Program of Special Coordination Funds for Science and Technology of Japan's Ministry of Education, Culture, Sports, Science and Technology. The authors also appreciate the financial aid provided by the Grant-in-Aid for Scientific Research (A) No. 22246058

\section{References}

1. Zhang, D., Ueda, T. and Furuuchi, H., Fracture Mechanisms of Polymer Cement Mortar (PCM)Concrete Interfaces, Journal of Engineering Mechanics, ASCE (to be printed).

2. Zhang, D., Ueda, T. and Furuuchi, H., Average Crack Spacing of Overlay-Strengthened RC Beams, Journal of Materials in Civil Engineering, ASCE, 23(10), October 2011, pp. 1460-1472, DOI: 10.1061/(ASCE)MT.1943-5533. 0000316.

3. Zhang, D., Ueda, T. and Furuuchi, H., Intermediate Crack Debonding of Polymer Cement Mortar Overlay-Strengthened RC Beam, Journal of Materials in Civil Engineering, ASCE, 23(6), June 2011, pp. 857-865, DOI: 10.1061/(ASCE) MT.1943-5533.0000240.

4. Zhang, D., Ueda, T. and Furuuchi, H., Concrete Cover Separation Failure of Overlay-strengthened Reinforced Concrete Beams, Construction and Building Materials, 26(1), 2012, pp. 735-745, DOI: 10.1016/j.conbuildmat.2011.06.082. 